\title{
Europe is Showing the Way
}

\author{
Karin Jöns Talks About the EU Guidelines for Mammography Screening and Breast Units
}

'Breast cancer is one of the great challenges of our times. And it is a challenge we have taken up.' These were the words of the President of the European Parliament, Josep Borrell Fontelles, last October in Brussels. A few minutes later the European Parliament was bathed in pink, the international colour of the fight against breast cancer (fig. 1). The dome of the Parliament building in the EU capital, gleaming pink above the roofs of all the EU institutions, national embassies and regional representations, symbolised the need for greater public awareness of breast cancer, since in the European Union breast cancer is diagnosed every 2 minutes and kills one woman every 6 minutes. What it did above all was to urge the national governments of the EU-25 to show greater commitment to the early detection and treatment of breast cancer. However good the EU guidelines are, they are worthless if they are not put into practice in the Member States, in other words if the main contents are not implemented in the national health systems. The point is that the European Union cannot force its Member States to do this. Health policy comes under the principle of subsidiarity and is therefore almost entirely a national responsibility.

However, the European Union took up the fight against breast cancer long before 2006. It all began in the late 1980s with the 'Europe against Cancer' programme, which also saw the birth of the European Breast Cancer Network (EBCN). The 'Europe against Cancer' action programme adopted by the European Parliament made it possible for the first time for the European Commission to establish a network of breast cancer experts not just from what were then the 12 EU Member States, but also from - to take some examples - Sweden, Norway, Switzerland, the USA and the WHO. The task of this network of experts was to exchange international research results and practical experiences in order to identify the best way to reduce the high breast cancer mortality rate throughout Europe. The work of the network, which has been ongoing ever since and now includes other tasks, has more than proved its worth! The EBCN was able to come up with its first set of appropriate recommendations as early as 1992, experience in Scandinavia, the Netherlands, the USA and the United Kingdom in particular having shown that quality-assured, population-based mammography screening can be very successful relatively quickly.

It is particularly disgraceful, then, that even today, 13 or 14 years later, mammography screening has been introduced country-wide in only 11 of the 25 Member States, and even then in some cases with serious shortcomings. Even Germany, the wealthiest country in the EU, is going to find it difficult to provide country-wide screening by the end of 2007, and in Austria, for example, there has to date not even been a single pilot project that meets the EU guidelines. All of the EU's hopes are currently pinned on a pilot project scheduled for January 2007 in Vienna. To avoid any misunderstandings, pilot projects are not designed to examine whether screening is useful. This has already been clearly proven scientifically, most recently at the Milan Global Summit on Mammography Screening in 2002. Pilot projects are intended to try to resolve organisational issues that differ from country to country.

The fact that many countries are still having so many problems in introducing mammography screening has, in the case of the old EU Member States, less to do with money and much more to do with the particular interests of the various players in their health systems. Health systems that are run on a national basis manage rather better here. But if the political and medical will is there, introducing screening in accordance with EU guidelines is both affordable and, today, fairly quickly achievable. Hungary, for example, has already shown us that it can be done.

By the way, if we take the highest price in the EU, it costs a maximum of EUR 1 per person in investment costs for the technical development of nationwide mammography screening in accordance with the EU guidelines, that is, for women aged between 50 and 69 . There is also the cost of specialised

\begin{tabular}{|c|c|}
\hline KARGER & (c) 2006 S. Karger GmbH, Freiburg \\
\hline $\begin{array}{l}\text { Fax +49 } 7614520714 \\
\text { E-mail Information@Karger.de } \\
\text { www.karger.com }\end{array}$ & $\begin{array}{l}\text { Accessible online at: } \\
\text { www.karger.com/brc }\end{array}$ \\
\hline
\end{tabular}


training for all staff working on the screening, which requires a further one-off investment of 25 cents per person. This means that EUR 1.25 per person creates the conditions for reducing the breast cancer mortality rate by up to $35 \%$, according to the WHO. The running costs would soon be offset by the use of less cost-intensive types of treatment and the fact that other social follow-up costs for the health system are no longer incurred. By using the screening procedure that will be described in the following, 16 women's lives could be saved every day in Germany alone and one woman every day as well in Austria as in Switzerland.

The EU guidelines recommend one screening unit for approximately every million people, comprising one mammography centre and two mobile mammography units which tour the area, a central results centre and an assessment centre for diagnostic clarification.

Germany, for instance, should need 82 screening units, but because of the division of responsibilities in the federal system 93 units are currently being set up. The difference should not be any more than this, however, because otherwise the critical number of women aged 50-69 to be screened, which is absolutely essential for quality-assurance purposes, could not be guaranteed. Deviations from the EU guidelines are therefore entirely acceptable but only up to a certain point. Austria would need 8-9 screening units, while Switzerland would need 7-8.

Mammography screening according to the EU guidelines basically involves the following:

- population-based invitation to all women aged between 50 and 69 (observing data protection requirements) every 2 years to have a voluntary breast X-ray paid for by their sickness fund/health insurer;

- blind double reading of the mammograms and, where necessary, confirmation by a third radiologist;

- where necessary, further diagnostic tests to clarify any findings (ultrasound, biopsy, MRI);

- all radiologists, pathologists and medical radiographers involved in the screening must be specialised in benign and malignant diseases of the breast, with radiologists, for instance, required to read the mammograms of at least 5000 women per year in order to have a trained eye;

- strict standards and regular checks on equipment at the lowest possible exposure dose and the highest image resolution quality by independent reference centres.

Provided that they have had the appropriate further training, independent radiologists can apply either to work as second readers in the screening process or to run a screening unit.

If screening is to be successful, it is important that there is a high level of acceptance among women. The aim is to involve $70 \%$ of all women aged $50-69$. However, women should be informed about the disadvantages as well as the advantages, because they should be free to choose whether to attend screening or not. Studies have shown that of one million women screened 11200 were found to have carcinomas, of which 14

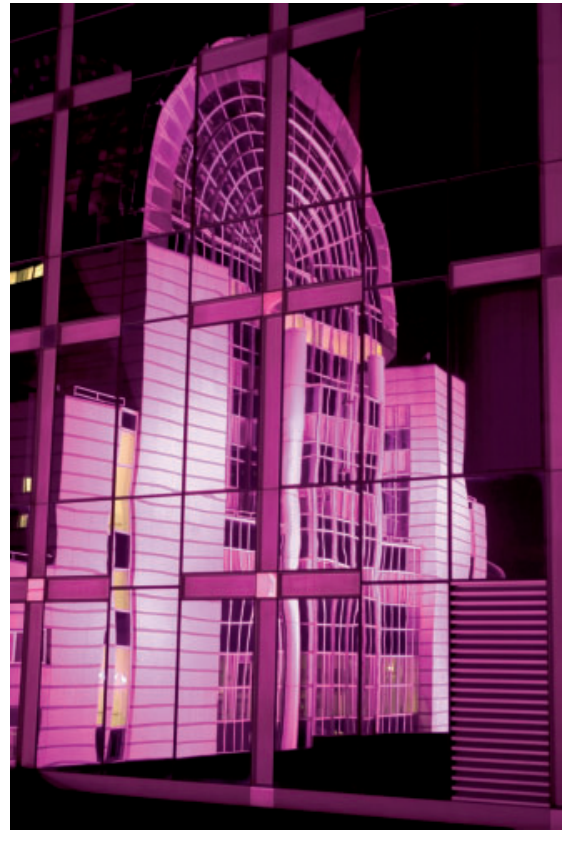

Fig. 1. The European Parliament bathed in pink light in October 2000 .

were actually caused by the radiation during screening. This sort of information can often make it easier for women to decide. Women should also be told that they will have a diagnosis within 7 days. Many countries have realised that it is best not to give women unclear or positive results at weekends.

We now also have the first clear indications that screening is useful for women from the age of 40 as well. The mortality rate in this age group could be cut by around 19\%. But these findings are not yet evidence-based. The screening interval for this age group would also have to be different, but this too is not yet evidence-based. This is why the European Parliament, the European Commission and the experts are for the time being only calling for screening from age 50. At this point it serves no purpose - in fact it is actually counterproductive - to invite women already now from the age of 40 , and in addition to screen them in the same interval as women from 50, as it is currently happening in Austria.

What we need to do repeatedly, however, is to remind the national governments of the EU Member States of the decisions taken by the Council of Ministers in Brussels with their unanimous agreement. They cannot vote for the Council Recommendation on cancer screening in Brussels in December 2003, and then behave at home as if this recommendation did not exist.

Even the best screening is pointless if the subsequent treatment is inadequate or even wrong. This is why the fourth version of the EU guidelines, published in April 2006, which runs to 416 pages, now also contains not just guidelines for digital mammography screening, but also guidelines for treatment in breast units, thus taking a step further towards better quality. There is now evidence that patients who are treated in specialised centres or hospital departments have not only a better 
quality of life, but also better chances of recovery. In this context the resolution of the European Parliament on 'Breast cancer in the enlarged European Union' of October 2006 calls on the Member States to ensure nationwide provision of multidisciplinary breast units by 2016 and also stresses once again the need for nationwide quality-assured screening.

The demand for EU guidelines for breast units dates back to June 2003, when the European Parliament, in its resolution on the Jöns Report, called for EU guidelines to be developed for interdisciplinary breast units, drawing on the first EUSOMA (European Society of Mastology) recommendations. These were put before Parliament 2 years later, in October 2005. It was inevitable that further public controversy would ensue, as it has done, because there are, of course, hospitals that call themselves breast units without having any specialisation whatsoever. There are also hospitals that call themselves breast units and which are indeed specialised, but where the quality is nowhere near the European standards, just as there are a few hospitals which do meet the European standards but do not call themselves breast units. Only one EU Member State claims to have breast units covering the whole country. According to the EU guidelines there should be one breast unit for every 250,000 inhabitants. Germany should therefore have 328 breast units, Austria 33 and Switzerland 30. But we still have a long way to go to achieve this.

Being a breast unit, according to the EU guidelines, means that:

- the whole team must be specialised in benign and malignant diseases of the breast,

- every case of breast cancer must be discussed pre- and post-operatively in interdisciplinary case conferences,

- at least 150 primary carcinomas must be operated on each year, with each surgeon operating on at least 50 primary carcinomas,

- the team must include at least 2 Breast Care Nurses,

- there are strict requirements concerning record-keeping,

- breast units should as a matter of principle take part in clinical studies and research projects,

- the whole team must undergo further training regularly,

- the units must be certified and recertified by an independent body.

It is important that the whole field of expertise should as far as possible be under one roof. A telephone conversation is no substitute for interdisciplinary cooperation outside the case conferences. Hospitals cannot combine their operation figures and claim to be breast units solely on the basis that they have consulted each other.

The question now is who should do the certifying? The Deutsche Krebsgesellschaft, for instance, was quicker off the mark than EUSOMA. Even before the EU guidelines were introduced, an objective procedure was organised, albeit with considerably lower quality requirements on quite central issues, which is why this certification in Germany cannot guarantee European quality standards. Only $20-40 \%$ of cases have to be discussed in interdisciplinary case conferences, for instance, and there is no requirement that these should be preand post-operative.

EUSOMA finally organised a pilot certification procedure, although it lacked transparency and objectivity and interpreted even the standards fixed for first certification so broadly that the European Board of EUROPA DONNA, the European coalition against breast cancer, withdrew from the project after just a few months. The procedure was finally abandoned as good example in March 2006 in Budapest at the annual conference of the European Cancer Network (ECN), an amalgamation (for financial reasons) of the existing EU cancer networks, including the European Breast Cancer Network. The ECN is now working on guidelines for the certification procedure itself.

Strictly monitored screening and interdisciplinary breast units conforming with the EU guidelines and certified in accordance with an EU guidelines procedure, along with a yet-tobe-developed EU guideline on the main contents for Breast Care Nursing, will hopefully help to ensure that one day every woman in Europe, regardless of where she lives, her social status and her level of education, receives the same optimum screening and treatment for breast cancer. There might then be an end to the huge disparities in survival rates, and to situations where in Poland, for example, even early-stage breast cancer still results in a mastectomy in $98 \%$ of cases, while the figure in France is just 28\%.

The fourth edition of the European guidelines, 'European Guidelines for quality assurance in breast cancer screening and diagnosis', which for the first time includes guidelines on digital screening and as mentioned on breast units, is published by the European Commission. It costs EUR 25 and can be ordered from the Office for Official Publications of the European Communities: http://bookshop.eu.int, ISBN: 92-79-01258-4, catalogue number: ND-73-06-954-EN-C. The EU guidelines are only available in English.

Postal address:

Office for Official Publications

Dissemination Unit

2 rue Mercier, 2985 Luxembourg

Tel. +352 2929 42855, Fax -42850

Karin Jöns MEP

European Parliament expert on breast cancer

Draftswoman of the European Parliament's 2003 report on breast cancer, Initiator of the EP's 2006 resolution on 'Breast cancer in the enlarged European Union' and Chair of the European Parliamentary Group on Breast Cancer 